\title{
Paciente haitiana embarazada de alto riesgo y utilidad del US en el diagnóstico diferencial en un PCR: presentación de un caso
}

\author{
High Risk Haitian Pregnant Patient and Utility of the \\ Ultrasound in the Differential Diagnosis in a Cardiac Arrest: \\ A Case Report
}

GABRIELA MARDONES SEGOVIA', JAVIERA VARGAS ZÚÑIGA², CLAUDIO GEORGE CARREÑO³. LUIS VIERA ${ }^{4}$, DUBY MORENO BLANCO ${ }^{3}$, ERICA BECKER WEISSER ${ }^{3}$

\begin{abstract}
In the recent years have been an increase in the number of pregnant patients of Haitian nationality in the Chilean public health service. This new population has a higher incidence of some pathologies as peripartum cardiomyopathy and sickle cell anemia which impact in the evolution of pregnancy and the anesthetic management of the peripartum. This article presents a case report of a 22 years-old hatian patient, with no known morbid history, who presents cardiac arrest during emergency cesarean section. In addition, it explains the method in which the diagnosis of peripartum cardiomyopathy was obtained, and how the reanimation and the differential diagnoses were guided by the use of ultrasonography. To conclude, it is crucial to develop screening methods to detect high-risk pregnant women and, at the same time, encourage the massification of tools, such as ultrasound [US], to manage critical situations that occurs more frequently in these patients.
\end{abstract}

\section{Resumen}

Durante el último tiempo ha existido un incremento en el número de pa-
Key words: Peripartum cardiomyopathy, heart failure, echocardiography.

Médico cirujano. Residente anestesiología HBLT/UDP.

Médico anestesiólogo HBLT/CAS, docente UDP.

Médico anestesiólogo HBLT, docente UDP.

Médico Anestesiólogo HBLT.

Fecha de recepción: 21 de marzo de 2018

Fecha de aceptación: 14 de abril de 2018

\section{ORCID}

https://orcid.org/0000-0002-7855-1553

\section{Correspondencia:}

Gabriela Mardones

Email: Gabriela.mardones.s@gmail.com 
cientes embarazadas de nacionalidad haitiana en el servicio de salud pública chileno. Esta nueva población trae consigo mayor incidencia de algunas patologías como cardiomiopatía del periparto y anemia falciforme, que condicionan la evolución del embarazo y el manejo anestésico del periparto. En este artículo se presenta el caso clínico de una paciente haitiana de 22 años, sin antecedentes mórbidos conocidos, que presenta un paro cardiorrespiratorio durante la cesárea de urgencia. Además, se explica la forma en que se obtuvo el diagnóstico de miocardiopatía del periparto, y cómo se guió la reanimación y los diagnósticos diferenciales mediante el uso de ultrasonografía. En conclusión se destaca que resulta imprescindible desarrollar métodos de screening para detectar embarazadas de alto riesgo y fomentar a su vez la masificación de herramientas, como el ultrasonido [US], para manejo de situaciones críticas que ocurren en mayor frecuencia en estas pacientes.

\section{Palabras clave:}

Cardiomiopatía

periparto, insuficiencia

cardíaca,

ecocardiografía.

\section{Introducción}

E xiste un incremento significativo de haitianas embarazadas en el servicio de salud pública de Chile, con determinantes sociales (analfabetismo, escaso control prenatal) y factores genéticos como la mayor incidencia de algunas patologías (cardiomiopatía del periparto y anemia falciforme) que condicionan la evolución del embarazo. Resulta imprescindible desarrollar métodos de screening para detectar embarazadas de alto riesgo y la masificación de herramientas, como el US, para manejo de situaciones críticas que ocurren más frecuentemente en estas pacientes.

\section{Presentación del caso}

Mujer haitiana de 22 años, analfabeta, embarazo de término, sin otros antecedentes conocidos.

Ingresa en trabajo de parto, se realiza ecografía con feto en p50-75, Líquiedo Amniótico normal y placenta normoinserta. Se inicia conducción oxitócica y analgesia peridural. Luego de 6 horas se indica cesárea por conducción fracasada/dilatación estacionaria. A pabellón ingresa hemodinámicamente estable. Se decide anestesia espinal (7,5 mg de Bupivacaina HB + Fentanyl $10 \mathrm{mcg}$ ). Inicia episodio de desaturación y bradicardia, se inicia ventilación asistida y se constata asistolía. Se indica extracción de feto y maniobras de Resucitación Cardiopulmonar avanzada (RCP).

A la intubación se observa contenido serohemático. Tras 3 ciclos de RCP recupera ritmo sinusal $\left(\mathrm{SpO}_{2} 85 \%\right)$. Se procede a monitorización invasiva y evaluación ecográfica (Figura 1), donde se observa vena cava de adecuado calibre; ausencia de trombos intracavitarios, derrame pericárdico, claudicación VD o líquido libre. Se observa si hipoquinesia global (Vídeo 1) y lineas B. Se sospecha miocardiopatía del periparto. Se inician Drogas Vasoactivas (Noradrenalina + Dobutamina) sin respuesta adecuada, nuevo episodio de bradicardia, desaturación y PCR/AESP, que revierte luego de 2 ciclos. Se adiciona morfina, nitroglicerina, furosemida y Adrenalina.

Cae nuevamente en PCR/AESP, ecoscopía muestra hipoquinesia global grave. Considerando pronóstico y sin más recursos (ECMO) se detienen maniobras.

Los resultados de la autopsia: pulmón congestivo, cardiomegalia e hipertrofia de ventrículo izquierdo.

\section{Discusión}

En USA la Miocardiopatía del Periparto tiene una prevalencia de 1:4.000 Recién Nacidos Vivos (RNV)[1], en cambio es considerada una condición endémica en Haití[2] (1:300 RNV) y en algunas zonas de África. Se caracteriza por disfunción sistólica del ventrículo izquierdo, síntomas de falla cardíaca, durante el último mes de gestación o cinco meses postparto[3]. Presenta complicaciones: taquiarritmias ventriculares, eventos tromboembólicos, miocardiopatía crónica y muerte, las que se han correlacionado con FEVI < 30-35\%[4]. Por este motivo el US se ha convertido en una herramienta fundamental para detección de pacientes de alto riesgo, con el fin de optimizar su manejo anestésico previniendo eventos catastróficos fatales.

Ante el creciente aumento de gestantes haitianas jóvenes que consulta en los servicios de urgencia de nuestro país, y frente la nula historia clínica que apor- 

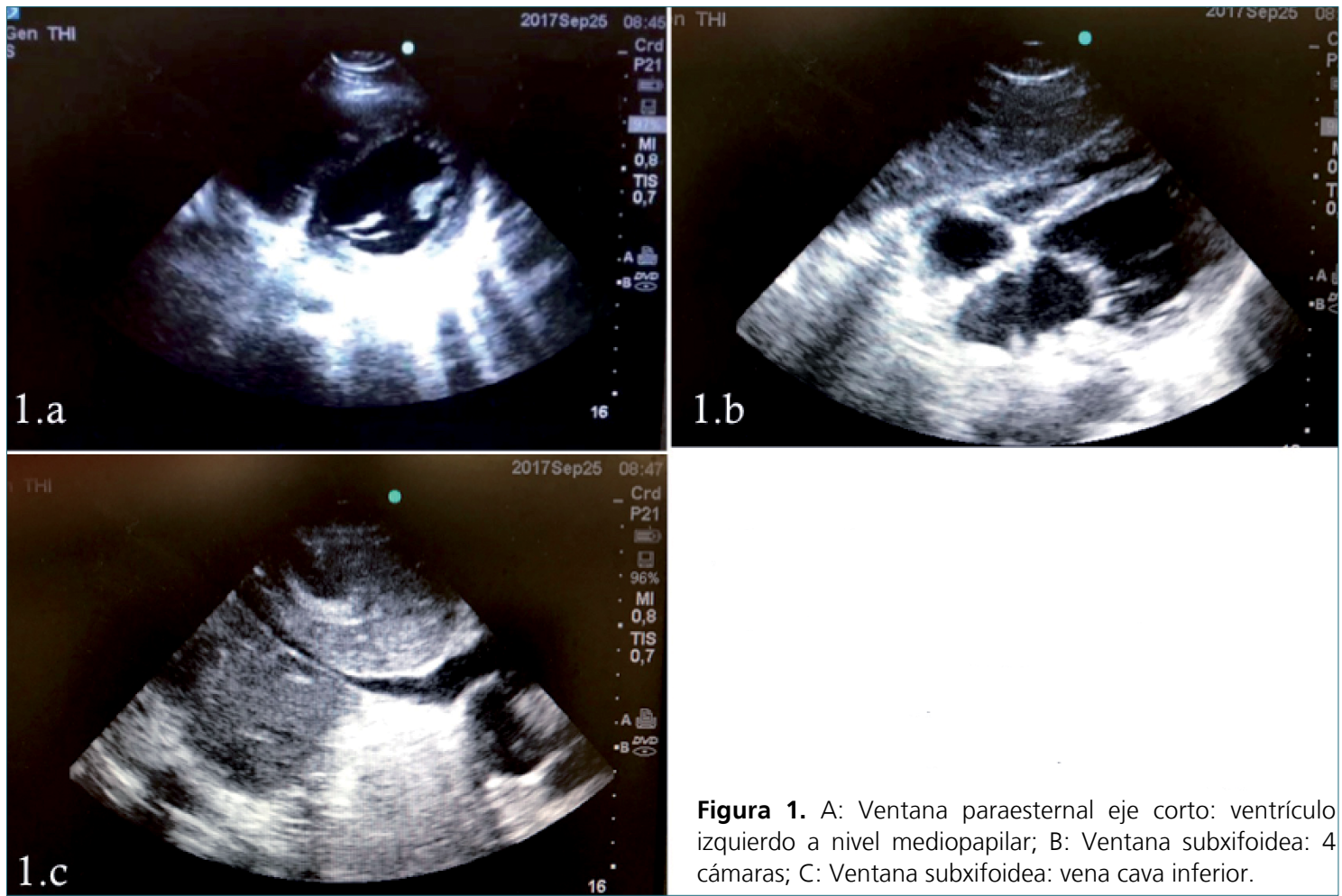

Figura 1. A: Ventana paraesternal eje corto: ventrículo izquierdo a nivel mediopapilar; B: Ventana subxifoidea: 4 cámaras; C: Ventana subxifoidea: vena cava inferior.

tan; sumado a la barrera idiomática; consideramos de vital importancia masificar y generar estrategias, tales como la utilización del US para evaluar función cardiaca ante sospecha diagnóstica, descartar diagnósticos diferenciales y guiar la conducta ante eventos catastróficos.

Comité de ética informado.

\section{Referencias}

1. Mielniczuk LM, Williams K, Davis $\mathrm{DR}$, et al. Frequency of peripartum cardiomyopathy. Am J Cardiol 2006;97:1765-8.

2. Fett JD, Christie LG, Carraway $\mathrm{RD}$, et al. Five- year prospective study of the incidence and prognosis of peripartum cardiomyopathy at a sin- gle institution. Mayo Clin Proc 2005;80:16026.

3. Demakis JG, Rahimtoola SH. Peripartum cardiomyopathy. Circulation 1971;44:964-68.
4. Elkayam U. Clinical characteristics of peripartum cardiomy- opathy in the United States: diagnosis, prognosis, and man- agement. J Am Coll Cardiol 2011; 58: 659-670 [PMID: 21816300 DOI: $10.1016 /$ j. jacc.2011.03.047] 